\title{
Refractory pemphigus vulgaris treated with rituximab and mycophenolate mofetil ${ }^{*}$
}

\author{
Stephanie Del Rio Navarrete Biot ${ }^{1}$ \\ Ricardo Barbosa Lima ${ }^{1}$ \\ Luiz Paulo José Marques ${ }^{1}$
}

\author{
Joanna Pimenta de Araujo Franco ${ }^{1}$ \\ Henrique Novo Costa Pereira ${ }^{1}$ \\ Carlos José Martins ${ }^{1}$
}

DOI: http://dx.doi.org/10.1590/abd1806-4841.20143128

\begin{abstract}
The main treatment for pemphigus vulgaris are systemic corticosteroids and immunosuppressive agents, but due to adverse reactions and therapeutic failure, new drugs such as rituximab and mycophenolate mofetil have been used. In this case report are described two cases of severe pemphigus vulgaris refractory to various treatments, with resolution after use of rituximab and mycophenolate mofetil, associated with corticosteroids. A higher-than-usual dose of rituximab was employed, without the occurrence of serious adverse reactions. Mycophenolate mofetil was added as adjunctive therapy due to lack of response to azathioprine.
\end{abstract}

Keywords: Antibodies, monoclonal; Immunosuppressive agents; Pemphigus

\section{INTRODUCTION}

Pemphigus vulgaris (PV) is a potentially fatal autoimmune bullous disease with a mortality rate around $5 \% .{ }^{1}$ The main treatment are systemic corticosteroids associated with immunosuppressants, but due to adverse reactions and treatment failure new therapeutic drugs have been prescribed, such as ritux$\mathrm{imab}^{2}$ and mycophenolate mofetil (MMF). ${ }^{3,4}$ Rituximab is an anti-CD20 monoclonal antibody that causes the depletion of B lymphocytes and B pre-lymphocytes. Initially developed for the treatment of nonHodgkin lymphoma, it has been shown to be an excellent option for autoimmune diseases like PV. ${ }^{2} \mathrm{MMF}$ is a relatively new immunosuppressant. ${ }^{3}$ It acts by specifically inhibiting activated T lymphocytes, with a more selective action, and with the advantage of being less mutagenic regarding azathioprine., ${ }^{4,5,6}$ Its use is approved for the prevention of solid organs allograft rejection and for lupus nephritis. Several studies point out its efficacy in the treatment of $\mathrm{PV}^{4.8}$ In this current study two cases of severe PV are reported, refractory to diverse treatments, with clinical resolution after use of rituximab and MMF combined with corticotherapy.

\section{CASE REPORTS}

Case 1 - Male, 47 years old, with diagnosis of $\mathrm{PV}$ and using prednisone $120 \mathrm{mg} /$ day for one month. At the examination he presented eroded and crusted lesions disseminated on the skin and erosions in the oral mucosa. Diagnosis of PV was histologically confirmed. Treatment was begun with pulses of methylprednisolone IV and oral prednisone between pulses. The patient progressed rapidly with severe worsening and infusions of intravenous immunoglobulin combined with prednisone and oral azathioprine were introduced (Figure 1A). After a period of improvement new lesions appeared and pulses of cyclophosphamide IV were administered, continuing with oral prednisone. Again there was improvement but after the fourth pulse a severe relapse occurred. Plasmapheresis was performed as well as a new pulse of cyclophosphamide with good response, but after seven days there was onset of new lesions (Figure 1B). At this point, treatment with rituximab was initiated. Prednisone was maintained and MMF was added. After the second cycle there was complete resolution of the clinical picture with hospital discharge, main-

Received on 09.07.2013.

Approved by the Advisory Board and accepted for publication on 13.09.2013.

Work carried out at the Hospital Universitário Gaffrée e Guinle, Universidade Federal do Estado do Rio de Janeiro (UNIRIO) - Rio de Janeiro (RJ), Brasil.

Conflict of interest: None

Financial funding: None

Universidade Federal do Estado do Rio de Janeiro (UNIRIO) - Rio de Janeiro (RJ), Brazil. 



FIGURE 1 (CASE 1): A: extensive erosion of lesions on the trunk and limbs, in the first phase of exacerbation of the disease before beginning treatment with intravenous immunoglobulin. B: dorsolumbar region after plasmapheresis, before beginning treatment with rituximab. C: dorsolumbar region after the end of second cycle of rituximab, three months after the first infusion

taining prednisone and MMF (Figure 1C). The patient was hospitalized for eight months and presented severe complications like infections and sepsis, before the initiation of rituximab, making use of several schemes of antibiotic therapy. During the outpatient clinic follow-up the MMF dose was maintained and the dose of prednisone was progressively reduced in the course of one year, until suspension. At this point, oral lesions appeared which persisted even after increase of prednisone. A new infusion of rituximab was started and the dose of MMF was increased, with resolution of lesions. One year after the last cycle of rituximab, the patient remains with the disease controlled with MMF $2.5 \mathrm{~g}$ / day and prednisone $10 \mathrm{mg}$ on alternate days. The therapeutic steps with drugs, doses, intervals and duration, are described in table 1.

Case 2 - Female, 46 years old, with hypertension and diabetes, both difficult to control, presented bullous lesions and erosions, with purulent secretion, disseminated on the scalp, face, trunk and limbs. Diagnosis of PV was confirmed histologically. She was hospitalized and submitted to treatment with antibiotic therapy, pulses of methylprednisolone IV and pulses of cyclophosphamide IV, with monthly intervals, besides oral prednisone and azathioprine. She achieved almost complete remission of lesions after the second pulse of cyclophosphamide, with hospital discharge. After the fifth pulse she presented leucopenia and after the sixth pulse there was relapse of the disease (Figure 2A). The patient was hospital- ized again and rituximab infusions were administered with two-week intervals, maintaining oral prednisone and azathioprine. There was improvement in the trunk lesions, but worsening of the facial ones, even after the third infusion of rituximab (Figures 2B and $3 \mathrm{~A})$. As a consequence, together with the fourth infusion the prednisone dose was increased and azathioprine replaced with MMF, with progressive improvement and hospital discharge after two months of hospitalization (Figure 3B). Since then the prednisone dose was progressively reduced and two years after hospital discharge, the patient remains with the disease under control with MMF 1g/day and prednisone $5 \mathrm{mg} /$ day (Figure 3C). The therapeutic steps, with drugs, doses, intervals and duration, are described in table 2.

\section{DISCUSSION}

Rituximab is indicated mainly for patients with PV refractory to at least two therapeutic modalities. ${ }^{2,9}$ The most used schemes are the four infusions per week at a dose of $375 \mathrm{mg} / \mathrm{m}^{2}$ and the one of two infusions of $1 \mathrm{~g}$ with two-week interval. They are approved, respectively, for the treatment of B cell nonHodgkin lymphomas, and for rheumatoid arthritis refractory to therapy with anti-TNF $\alpha .^{10}$ The most common collateral effects are related to infusion (headache, fever, nausea, vomiting, pruritus, hypotension). Severe effects such as sepsis and opportunistic infections are rare. ${ }^{9}$ In a study of 103 patients with PV 
TABLE 1: Therapeutic phases - case 1

\begin{tabular}{|c|c|c|}
\hline Phases & Medications & Period \\
\hline 1 st & $\begin{array}{l}2 \text { cycles of pulse therapy with MPD } 1 \mathrm{~g} \text { IV, for } 3 \text { days, with weekly interval and } \\
\text { PDN } 60 \mathrm{mg} / \text { day, between pulses. }\end{array}$ & 2 weeks \\
\hline 2nd & $\begin{array}{l}3 \text { cycles of infusions of IVIG } 2 \mathrm{~g} / \mathrm{kg} / \text { cycle, divided in } 4 \text { days, with intervals } \\
\text { of } 2 \text { to } 3 \text { weeks, PDN } 120 \mathrm{mg} / \text { day and AZA } 150 \mathrm{mg} / \text { day. }\end{array}$ & 9 weeks \\
\hline $3 \mathrm{rd}$ & $\begin{array}{l}4 \text { pulses of CPP } 500 \mathrm{mg} / \mathrm{m}^{2} \mathrm{IV} \text {, with interval of } 3 \text { weeks between pulses } \\
\text { and PDN } 120 \mathrm{mg} / \text { day. }\end{array}$ & 9 weeks \\
\hline 4 th & 3 sessions of PPH with 1 pulse of CPP on fourth day, and PDN $120 \mathrm{mg} /$ day & 2 weeks \\
\hline 5 th & $\begin{array}{l}\text { RTX, } 2 \text { cycles of } 4 \text { weekly infusions of } 375 \mathrm{mg} / \mathrm{m}^{2} \text {, with } 4 \text {-week intervals between cycles, } \\
\text { PDN } 120 \mathrm{mg} \text { / day and MMF } 2 \mathrm{~g} / \text { day. Hospital discharge after } 8 \text { months. }\end{array}$ & 12 weeks \\
\hline 6th & $\begin{array}{l}\text { Outpatient clinic treatment with } \mathrm{MMF} 2 \mathrm{~g} / \text { day and progressive reduction of PDN } \\
\text { dose for } 1 \text { year, until suspension, when relapse of lesions occurred, refractory to } \\
\text { reintroduction of PDN } 80 \mathrm{mg} / \text { day. }\end{array}$ & 12 weeks \\
\hline 7 th & $\begin{array}{l}\text { New hospitalization for administration of RTX, } 1 \text { cycle of two infusions of } 1 \mathrm{~g} \text {, with a } \\
\text { two-week interval, PDN } 80 \mathrm{mg} / \text { day and MMF } 2.5 \mathrm{~g} / \text { day. Hospital discharge after } 4 \text { weeks. }\end{array}$ & 4 weeks \\
\hline 8th & $\begin{array}{l}\text { Outpatient clinic treatment with progressive reduction of PDN dose. One year after the } \\
\text { last RTX infusion, the disease remains controlled with MMF } 2.5 \mathrm{mg} \text { and PDN } \\
10 \mathrm{mg} \text { on alternate days. }\end{array}$ & 12 weeks \\
\hline
\end{tabular}

Note: $\mathrm{MPD}$ = methylprednisolone; $\mathrm{PDN}$ = prednisone; IVIG = intravenous immunoglobulin; AZA = azathioprine;

$\mathrm{CPP}=$ cyclophosphamide; $\mathrm{PPH}=$ plasmapheresis; $\mathrm{RTX}=$ rituximab; $\mathrm{MMF}=$ mycophenolate mofetil.
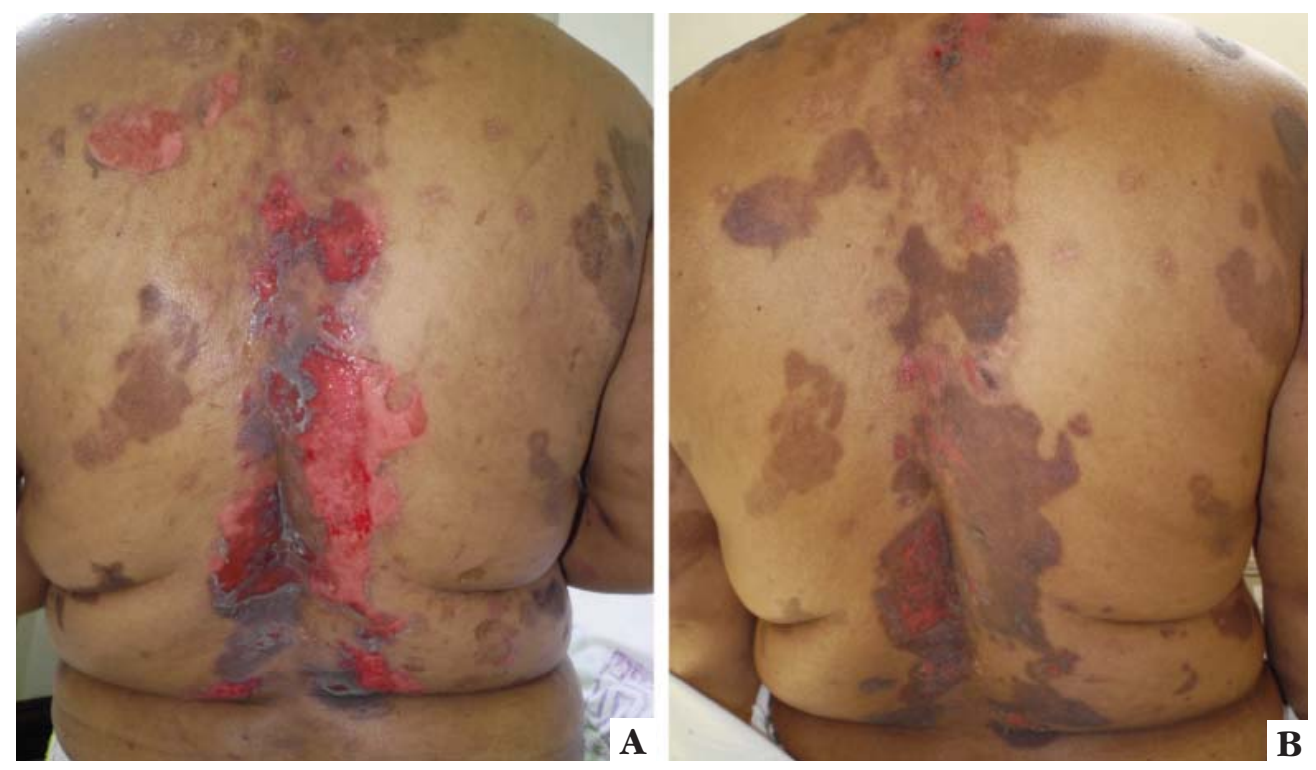

Figure 2 (CASE 2): A: erosions in dorsolumbar region after relapse of the disease, during pulse therapy with cyclophosphamide plus prednisone and azathioprine orally. B: improvement of lesions in dorsolumbar region, after the third rituximab infusion

who were treated with rituximab, Schmidt and collaborators reported complete remission in $77 \%$ and partial remission in $21 \%$ of the patients. Severe collateral effects occurred in $14 \%$ of the patients. ${ }^{2}$ In the two cases reported in this work a greater number of infu- sions of rituximab were necessary until the resolution of lesions, with no occurrence of adverse reactions.

MMF is considered by some authors the best corticosteroid-sparing drug for bullous diseases. ${ }^{4,5}$ The recommended dose is $35 \mathrm{mg}-45 \mathrm{mg} / \mathrm{kg} /$ day, adminis- 

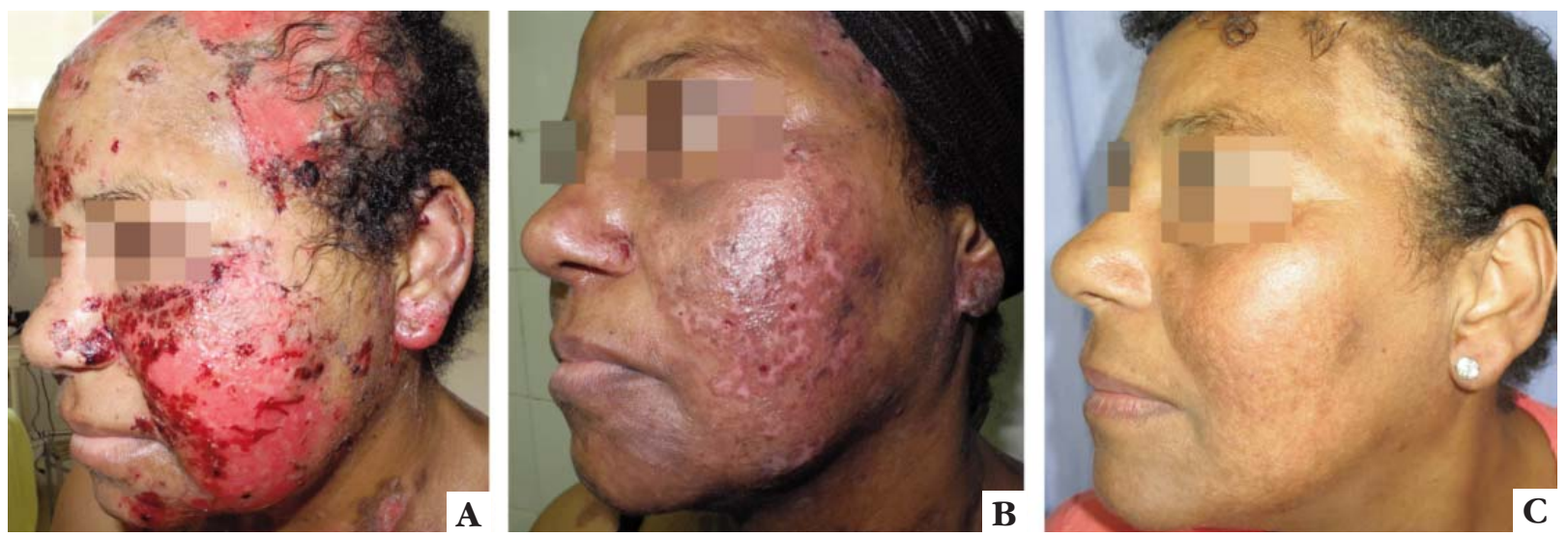

FIGURE 3 (CASE 2): A: erosions on face and scalp, after the third rituximab infusion. B: healing of lesions on the face three weeks after the fourth rituximab infusion, increase of prednisone dose and introduction of MMF. C: face and scalp 18 months after the end of rituximab infusions

TABLE 2: Therapeutic phases - case 2

\begin{tabular}{|c|c|c|}
\hline Phases & Medications & Duration \\
\hline 1 st & $\begin{array}{l}\text { Pulse therapy with MPD } 1 \mathrm{~g} / \text { day IV, for } 3 \text { days, and } 6 \text { pulses CPP 500mg/m2 IV, with } \\
\text { monthly intervals and PDN 30mg/day and oral AZA 150mg/day between pulses. } \\
\text { Hospital discharge after second pulse of CPP. Following pulses in a day-hospital schedule. }\end{array}$ & 22 weeks \\
\hline 2nd & $\begin{array}{l}\text { New hospitalization for administration of RTX, } 4 \text { infusions of } 1 \mathrm{~g} \text {, with } 15 \text {-day interval, } \\
\text { continuing PDN 30mg/day and AZA 150mg/day up to the } 4 \text { th infusion. With the } 4 \text { th } \\
\text { infusion, PDN was increased to } 80 \mathrm{mg} / \text { day and AZA was replaced by MMF } 1.5 \mathrm{~g} / \text { day. } \\
\text { Hospital discharge after } 2 \text { months. }\end{array}$ & 9 weeks \\
\hline $3 \mathrm{rd}$ & $\begin{array}{l}\text { Outpatient clinic treatment with MMF } 1.5 \mathrm{~g} / \text { day and progressive decrease of PDN dose. } \\
\text { Two years after the last RTX infusion, the disease remains controlled with } \\
\text { MMF } 1 \mathrm{~g} / \text { day and PDN } 5 \mathrm{mg} / \text { day. }\end{array}$ & 24 weeks \\
\hline
\end{tabular}

Note: $\mathrm{MPD}=$ methylprednisolone; $\mathrm{CPP}=$ cyclophosphamide; $\mathrm{PDN}=$ prednisone; $\mathrm{AZA}=$ azathioprine; $\mathrm{RTX}=$ rituximab;

$\mathrm{MMF}=$ mycophenolate mofetil.

tered every 12 hours with meals. The dose should be gradually increased to avoid gastrointestinal effects. ${ }^{3,45}$ The drug is presented in $500 \mathrm{mg}$ capsules and there is another form, sodium mycophenolate, presented in $360 \mathrm{mg}$ capsules, equivalent to $500 \mathrm{mg}$ of $\mathrm{MMF}^{4}$

In a study with 36 cases of patients with PV and pemphigus foliaceus treated with rituximab, the most used concomitant drugs were prednisone and MMF, in $53 \%$ and $50 \%$ of the cases, respectively. ${ }^{10}$
The high cost and the off-label condition are factors that limit its provision by Unified Health System (SUS - Sistema Único de Saúde). In the reported cases, rituximab was supplied by the hospital unit and the MMF by the nephrology sector, until obtained by SUS with a judicial warrant.

The reports in the literature and the results obtained in the described cases indicate that rituximab and MMF are safe, effective drugs, with lasting results, revealing themselves as valuable therapeutic options for severe and refractory PV. ${ }^{1}$ 


\section{REFERENCES}

1. Sorce M, Aricò M, Bongiorno MR. Rituximab in refractory pemphigus vulgaris. Dermatol Ther. 2008;21 Suppl 1:S6-9.

2. Schmidt E, Goebeler M, Zillikens D. Rituximab in severe pemphigus. Ann N Y Acad Sci. 2009;1173:683-91.

3. Koga H, Ishii N, Hamada T, Karashima T, Nakama T, Yasumoto S, et al. Sucessful treatment with mycophenolate mofetil of four Japanese patients with pemphigus vulgaris. Eur J Dermatol. 2010;20:472-5.

4. Bressan AL, Silva RS, Fontenelle E, Gripp AC. Immunosuppressive agents in Dermatology. An Bras Dermatol. 2010;85:9-22.

5. Orvis AK, Wesson SK, Breza TS Jr, Church AA, Mitchell CL, Watkins SW. Mycophenolate mofetil in dermatology. J Am Acad Dermatol. 2009;60:183-99.

6. Beissert S, Werfel T, Frieling U, Böhm M, Sticherling M, Stadler R, et al. A comparison of oral methylprednisolone plus azathioprine or mycophenolate mofetil for the treatment of pemphigus. Arch Dermatol. 2006:142:1447-54.

7. Esmaili N, Chams-Davatchi C, Valikhani M, Farshidfar F, Parvaneh N, Tamizifar B. Treatment of pemphigus vulgaris with mycophenolate mofetil as a steroid-sparing agent. Eur J Dermatol. 2008;18:159-64.

8. Powell AM, Albert S, Al Fares S, Harman KE, Setterfield J, Bhogal B, et al. An evaluation of the usefulness of mycophenolate mofetil in pemphigus. $\mathrm{Br} \mathrm{J}$ Dermatol. 2003;149:138-45.

9. Schmidt E, Hunzelmann N, Zillikens D, Bröcker EB, Goebeler M. Rituximab in refractory autoimmune bullous diseases. Clin Exp Dermatol. 2006;31:503-8.

10. Kasperkiewicz M, Eming R, Behzad M, Hunzelmann N, Meurer M, Schulze-Koops $\mathrm{H}$, et al. Efficacy and safety of rituximab in pemphigus: experience of the german registry of autoimmune diseases. J Dtsch Dermatol Ges. 2012;10:727-32.
MAILING ADDRESS:

Stephanie Del Rio Navarrete Biot

Rua Mariz e Barros, 775 - Tijuca

20270-004 - Rio de Janeiro - RJ

Brazil

E-mail: tupibiot@hotmail.com

How to cite this article: Biot SDRN, Franco JPA, Lima RB, Pereira HNC, Marques LPJ, Martins CJ. Refractory pemphigus vulgaris treated with rituximab and mycophenolate mofetil. An Bras Dermatol. 2014;89(6):980-4. 